\title{
Social Constructivism in Medical School Where Students Become Patients with Dietary Restrictions
}

This article was published in the following Dove Press journal:

Advances in Medical Education and Practice

\section{Eileen F Hennrikus (D) \\ Michael P Skolka ${ }^{2}$ \\ Nicholas Hennrikus ${ }^{3}$ \\ 'Department of Medicine, Penn State College of Medicine, Hershey, PA, USA; ${ }^{2}$ Department of Neurology, Mayo Clinic Hospital, Rochester, MN, USA; ${ }^{3}$ Chula Vista Learning Community Charter School, Chula Vista, CA, USA}

\section{Video Abstract}

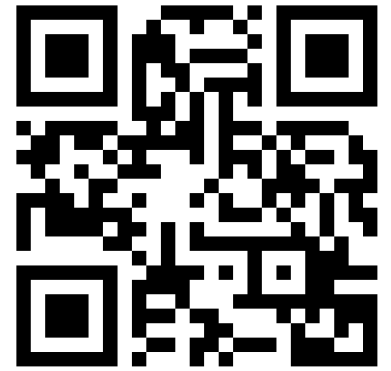

Point your SmartPhone at the code above. If you have a $Q R$ code reader, the video abstract will appear. Or use: https://youtu.be/gsADFoLUAvc
Correspondence: Eileen F Hennrikus Email ehennrikus@pennstatehealth.psu. edu
Background: Experiential vertical integration of basic science with clinical concepts remains a challenge in medical school curricula. In addition, training physicians in nutritional competency that translates into patient care is a challenging endeavor ranging from biochemical mechanisms to socioeconomic challenges.

Methods: Employing a social constructivism paradigm, we implemented a collaborative cook-off competition in a basic science course where 140 first-year medical students per year translated their studies of inborn errors of metabolism, energy metabolism, micronutrients and immunology into edible creations intended for people with disorders requiring dietary management. After learning about the disorders in lecture, problem-based learning, teambased learning and through patient interviews, four problem-based learning groups ( 7 students per group) were assigned to prepare food dishes for one of the five assigned disorders. Together, students researched the dietary requirements, shopped, paid for, prepared, presented and shared their food. To the class, faculty and re-invited patients, the groups explained the dietary restrictions, the chosen ingredients, how they prepared the food, and why their dish was suitable for the disorder. Each category was judged and awarded a first-place food prize with a grand prize at the end. At the completion of the course, student feedback was elicited via anonymous evaluations. Over 3 years, 380 comments were collected. We used grounded theory to generate a codebook that was then analyzed by the authors for overarching themes.

Results: Qualitative results described three major themes: increased relevance of basic science to real life, increased empathy towards complying with dietary restrictions, and increased student group cohesiveness.

Conclusion: The patient-centered cook-off competition taught students the relevance of basic science but in addition, it taught empathy towards the patient experience. We also discovered that the process of food preparation was a bonding experience that promoted collaboration, cohesiveness and friendship within the student class.

Keywords: biochemistry, immunology, nutrition, basic science, empathy

\section{Introduction}

Integrating curriculum has become a medical school directive. There is vertical integration between the basic and clinical sciences, horizontal integration between different subject areas and longitudinal integration between different specialties. ${ }^{1}$ Problem-based learning (PBL) has been a popular form of vertical integration felt to stimulate deeper, lifelong learning. ${ }^{2}$ PBL, case-based learning and simulation activities are methods of contextualization of basic science whereby the applicability of a basic science concept is demonstrated in a clinical scenario. ${ }^{2-4}$ 
Social constructivism theory is a model of collaborative learning within a cultural and social context. Learners actively co-construct meaning and understanding together by applying concepts using a variety of communicative methods and then sharing their new knowledge with peers. Faculty function as guides and facilitators, providing opportunities and incentives to the learners. ${ }^{5}$ We attempted to implement a social constructivism method of learning in the medical students' first basic science course, Scientific Principles of Medicine, to develop vertical integration of the basic sciences with clinical medicine.

Nutrition science has been used as a vertical, horizontal and longitudinal pedagogy to integrate the basic science with diseases of lifestyle and socioeconomic influences. ${ }^{6,7}$ Dietary and lifestyle modifications are frequently first-line treatment strategies for many conditions. ${ }^{8,9}$ Yet, nutritional education is deficient in medical education which is why many physicians report feeling uncomfortable and unprepared to provide nutritional counseling to their patients. ${ }^{10,11}$ Students have expressed that nutrition education in medical school would be improved if innovative learning strategies could be incorporated early and longitudinally through their curriculum. ${ }^{12}$ Various nutritional active learning modalities have been described, including a simulated grocery store where students analyzed labels and answered questions, problem-based learning (PBL), team-based learning (TBL), and online modules. ${ }^{13-17}$ These are all examples of innovative ideas that medical educators seek to engage students in active, experiential, and relevant learning methods. ${ }^{18,19}$

At our medical school, students learn amino acid, protein and lipid metabolism in their introductory basic science course, they learn about micronutrients, absorption and elimination in their gastroenterology course and they learn about the complications and treatments of excessive lipids and carbohydrates in their cardiology and endocrinology courses. We used the social construct of meal preparation and food sharing in this first basic science course cook-off competition exercise. This social constructivism method is not used again in our medical school until the fourth year, two-week, elective, Culinary Medicine, where medical students prepare and share food with senior citizens. ${ }^{20}$

In addition, medical schools are trying to bridge the gap between the basic science encountered in medical school's first 2 years and the clinical, humanistic curriculum students will encounter later in clinical rotations. ${ }^{21,22}$ Educators also try to develop activities that encourage teamwork and enhance the class community. ${ }^{23,24}$ These factors are important in creating a supportive, learning environment. But these curricular innovations still portray the student as the physician treating the patient. We describe an innovative, experiential intervention where the student becomes the patient. As the patient, they must create food guided by the medical nutritional requirements dictated by their assigned disorder of metabolism. The assignment was designed within an educational social construct through collaboration and community.

The main objective of our educational intervention was to vertically integrate basic science metabolic and immunologic pathways with clinical disease using nutrition in a constructivist educational model. What we discovered, however, was that by sharing food in this simple cook-off competition, students had a much broader learning experience.

\section{Methods}

The data used in this study were approved as part of the education research registry, which was approved by the Penn State College of Medicine Institutional Review Board (\#STUDY00000123).

Scientific Principles of Medicine is a 13-week basic science course designed as the foundational medical course for 140 first-year medical students. The basic course structure consists of lectures, PBLs, TBLs, simulation sessions, review sessions and patient encounters. The course covers biochemistry, cell biology, genetics, cancer, immunology and microbiology foundations necessary for the subsequent organ block curriculum.

In order to increase the medical relevance of basic science, we used nutritional competency as the cornerstone and developed a student group cook-off competition. Each of the 20 PBL groups, consisting of 7 students per group, was randomly assigned 1 of the 5 disorders that had previously been studied in the course. Each of these disorders was discussed in the lecture and was further examined through a PBL case and/or through a patient interview in class. The PBLs and patient interviews provided a cultural, social, humanistic context to the disorders. The disorders were Maple Syrup Urine Disease (MSUD), Medium-chain acyl-CoA dehydrogenase (MCAD) deficiency, Phenylketonuria (PKU), Glycogen storage disease type I (von Gierke disease), and Celiac disease. These disorders highlight principles of inborn errors of metabolism, carbohydrate, fat and protein metabolism, micronutrients and immunology that require strict 
daily dietary modifications for the life of the patient. Each disorder was assigned to four PBL groups. The assignment was released during a Friday PBL session, 1 week before the scheduled cook-off competition (Appendix 1).

The groups were tasked to prepare, outside of class, a hors d'oeuvre style food dish consisting of 25-30 portions. Each group researched the dietary restrictions, selected a recipe, purchased the ingredients, and prepared the food together. The ingredients of each dish must be accurately prepared so that a person diagnosed with the disorder can eat the food without exacerbating their condition.

On the specified class day, students brought their prepared dishes during the usual 11:00 am -noon lecture time. The food dishes were then grouped by category, given a number from 1 to 4 , and displayed in the front of the lecture hall with ingredients and recipes attached. Each group gave a 2-3-minute creative presentation explaining the dietary restrictions in relation to the biochemical or immunologic deficiency, the ingredients, and the shopping/ cooking process for their specific dish. Five judges (guest patients who had spoken to the class about the challenges of living with the disorder, faculty and fellow students) listened to the presentations and sampled each dish. The judges were asked to consider creativity, taste, and dietary accuracy in their deliberations. In each category, each judge voted by raising one of the four numbered cards correlating to the dish of their choice. The winners of each category were then given a ribbon and food prizes. Lastly, the five winners of each category were judged, and a grand prize was awarded to the team with the best dish of the day. After the judging process, the entire class was invited to eat from noon to $1 \mathrm{pm}$. There was always enough food to provide lunch for the entire class.

\section{Data Collection}

Each year, at the end of the SPM course, all students were requested to submit an evaluation of the strengths and weaknesses of the course and of each of the classes. All responses were open-ended free text and voluntary. Over 3 years, 380 responses that included specific comments regarding the cook-off competition were isolated.

\section{Data Analysis}

Using grounded theory, the student comments were evaluated with a thematic analysis approach. ${ }^{25,26}$ Team members, MS and EH developed ideas about patterns and meanings. One team member (MS) assigned codes to repetitive ideas. All student responses were evaluated. ATLAS.ti 8.0 software was used to manage the data. Using the codebook developed by MS, two other team members (EH and $\mathrm{NH}$ ) each independently coded sections of relevant text from student responses. Updating and changing the codebook was done among the three members. Once verified and analyzed, compared and combined, codes were grouped into themes according to similarities and relationships. We used axial coding to identify sub-themes and themes and the crossconnections of concepts between them. The data were reviewed and re-analyzed until consensus between the three members was achieved and theoretical saturation was reached. Representative quotes were abstracted to illustrate the key features of the sub-themes and themes. ${ }^{27}$

\section{Results}

Three themes were extracted from student comments: relevance and application of nutritional biochemical knowledge, empathy towards patients with dietary restrictions and the enhancement of student bonding, collaboration and cohesiveness.

\section{Theme I: Relevance and Application of Nutritional Biochemical Knowledge}

Students expressed a new awareness of food's effect on the body and how diet can influence patient outcomes from a biochemical level to a clinical presentation.

I could always eat whatever I wanted. I never realized the intricacies of food and how food can have such different effects on different people.

I found it intellectually stimulating in seeing the variety of diets that were required to sustain different types of disease.

Although students were taught that these disorders required strict dietary restrictions, this exercise provided a deeper understanding of what that really meant. Students expressed a more profound realization and appreciation of how a strict diet can treat disease.

I really enjoyed this exercise. It helped me to get a better picture of the treatment of the different diseases.

It was a great way to introduce the different diseases and show students how difficult it can be to have a strict diet to manage certain diseases. 
Students expressed an appreciation for practicing and applying information learned in the classroom to real life. Using the social construct of preparing and sharing food made the process enjoyable. Adding a hint of competition and "showmanship" sparked student effort and added a cordial "game-like" atmosphere. Had the assignment been to individually write a recipe for each of the diseases, it is highly probable that the students would have found that to be a tedious exercise.

It was amazing to actually put into practice the stuff we were learning, and enjoy doing it.

This was a great initiative to apply things that we have learned from class. Eating free food was a bonus!

The project allowed students a chance to learn while having fun; this is something I feel leads to better understanding of material.

The student responses support the supposition that the process culminating in the cook-off competition was an exercise that achieved vertical integration of basic science principles to clinical medicine through a constructivism paradigm.

\section{Theme 2: Empathy Towards Patients}

The stage of social constructivism was developed earlier in the course and the theme of empathy was built upon by previous student-patient interactions in the course. Three of the five disorders had a class-patient interview. During these interviews, patients spoke to the class and answered student questions regarding living and coping with a chronic disease. ${ }^{22}$ Having these patients return in a role reversal, ie, the patients observe and evaluate the students, in a communal joyous setting, allowed for interactions of equality and friendship between students and patients. Students expressed difficulty in shopping, cooking and affording the expense of specific ingredients and the difficulty in avoiding ingredients commonly found in their usual food. Students were able to express their understanding of the patients' day-to-day life challenges to the "patient-judge."

It was also a good learning experience in understanding the difficulty of cooking for specific diseases.

The cook-off was a nice idea that gave us insight into how difficult it can be for patients to follow dietary restrictions of the diseases.
The cook-off was a nice break away from studying, and I think we learned a lot through thinking of what a patient with our assigned disease can eat.

Preparing a meal with dietary restrictions was in itself a challenge. But this assignment was just one class within the construct of the Scientific Principles of Medicine course where patients suffering from chronic conditions came and spoke to the students on a weekly basis. Through the cook-off assignment, students became personally aware of the difficulties patients endure living with a chronic condition. Having to actually step into a patient's life for a brief assignment allowed students to have a brief personal exposure to a chronic, unremitting condition.

I thought the cook-off was really fun and provided us with a really different way to see what living with a chronic condition entails.

I greatly appreciated this event, not only because of the enthusiasm each student brought, but also because I walked away with a greater appreciation for the barriers that patients face in preparing a meal within dietary restrictions, and the efforts taken to overcome those barriers. The challenges that we encountered preparing just one meal, these patients encounter every meal and every day.

\section{Theme 3: Student Collaboration and Cohesiveness}

The sharing of food is known to increase interpersonal closeness. ${ }^{28}$ Students commented on the preparation of food, the sharing of a meal, and the presentations to their peers as a collaborative experience that increased the cohesiveness within the groups and within the class. Students requested that the cook-off be moved up in the class schedule so that they could develop that cohesiveness earlier in the year, improving their collaboration within their PBL sessions.

During that time I was able to bond with my PBL group by making our meal together and also had a great time during the actual cook-off!

I found the preparation for the cook-off to be a great bonding moment for my group that could have definitely helped the group's cohesiveness early on.

Through cooking and preparing creative presentations, students developed a personal connection and appreciation of each other's talents and humor beyond the classroom. 
This was really fun. I liked working with my PBL group and it was really exciting seeing everyone's dish!

I loved the cook off! We have so many talented chefs in this class.

\section{Discussion}

The disorders chosen for the cook-off competition were selected to illustrate the biochemical and immunologic pathways that the students were studying in the course. Basic scientists presented the pathways in lecture, the knowledge base of Blooms taxonomy. ${ }^{29}$ The basic science knowledge was then contextualized in PBL where the basic science was applied to a clinical case. Every week, patients were invited to speak to the class about their experiences. In combination with the patient interviews, the cook-off competition was intended to translate the "book information" into real life. Strict nutritional requirements are needed to maintain normal life in patients with these disorders. For example, MSUD is an inherited defect in the enzyme complex needed to metabolize branched-chain amino acids. The diet requires very low protein content to prevent neurologic dysfunction, seizures and growth delay. MCAD deficiency is an inherited disorder that prevents the breakdown of medium-chain fatty acids. These children need a high carbohydrate and low-fat diet to prevent the development of non-ketotic hypoglycemia. PKU is an inherited defect in the enzyme that metabolizes phenylalanine. Children must avoid phenylalanine in their diet or suffer from severe irreversible neurologic delay. In von Gierke disease, the person has a deficiency in the enzyme that breaks down the liver's glycogen stores. When a person with von Gierke disease is in a fasting state, they are unable to convert their glycogen stores to glucose. These patients require a continuous supply of carbohydrate, frequently in the form of cornstarch, or they quickly become hypoglycemic and acidotic. Celiac disease was studied in the immunology section of the course. A person with celiac disease has an immune reaction to gluten resulting in intestinal inflammation and malabsorption. The treatment of celiac disease is a gluten-free diet.

In preparation for this cook-off activity, students studied the dietary requirements and treatments of diseases that they were taught in class. In addition, the students learned the challenges of abiding by certain nutritional restrictions. The students experienced the disease from a patient's perspective. The students became the patient by researching food groups, shopping, pricing and preparing the food. This cook-off activity required groups of students to collaborate outside of the classroom. This networking process improved the cohesiveness of the class. Sharing the food became a celebration.

Rising in the pyramid of Bloom's taxonomy, the students are first presented with the basic concepts in lecture, followed by a discussion of the concepts in cases presented in PBL. Next, the students analyzed the disease entity for the dietary restrictions and applied this knowledge when shopping for ingredients and developing a recipe. The students justified their reasoning to the class. Judges evaluated their edible creations. Out of the lecture hall, the students advanced their learning through social constructivism within their groups. In their PBL groups, students developed their own learning objectives and led their own discussions but were supervised by faculty facilitators. We advanced the implementation of Social Constructivism by moving out of the classroom and facilitating student responsibility for their learning and encouraging intrinsic motivation. Students collaborated outside of the classroom without direct faculty supervision: researching, shopping, and creating a biochemically correct, visually appealing and tasty food dish to share with their peers. Theoretically, if we assigned the students this task as "homework" without an outlet to perform and be judged, few students would participate and "do the extra work." However, organizing this task into a fun, low risk, "game-like" event enticed student participation. The students enjoyed presenting their edible creations in front of their peers and were motivated to compete for ribbons, cookies and chocolate bar prizes.

This simple assignment transcended the basic educational theory by transforming the student into the patient. Without developing an illness, most medical students study and treat patients without ever understanding how the patient feels. Students rarely "walk in a patient's shoes." Although teaching empathy was not a planned objective, empathy was a major lesson that resulted from this activity. Students had to follow "the doctor's advice" and they found that following this advice was often difficult. Medical school curriculum would benefit from more activities that place the student in the patient's shoes.

Lastly, the students enjoyed this educational process and had fun. They bonded within their groups. In the first year, the cook-off competition was held on the final day of class. Feedback returned saying that

I would like to make a recommendation that the cook-off happens early on in the course. I found the preparation for the cook-off to be a great bonding moment for my group that could have definitely helped the group's cohesiveness early on. 
In response to this feedback, we moved the cook-off to midsemester for the following year's class. As seen in subsequent student evaluations, moving the cook-off to mid-semester fostered collaboration and cohesiveness in the classroom.

Out of the 380 comments, only two comments in the first year were negative, stating that the cook-off was boring to watch other people eat. Adjustments were made to include volunteer students to judge and taste the food, to include the entire group in the presentations, to keep the process moving expeditiously by completing the judging and presentations simultaneously, award group food prizes after each disorder and involving the whole class in judging the presentations and deciding tie-breakers. There were no negative evaluations in the following years.

Students found the cook-off exercise engaging and relevant. Students actively participated, attained the knowledge, mastered the skills and applied their learning to create an appropriate and delicious food item. We anticipate that, in the future, when these students become physicians, a possible lasting impact of the cook-off will be a heightened sense of empathy demonstrated in their patient care. In addition, as reflected in the feedback comments from students, the impact of this educational experience translates into an understanding of the challenges in daily dietary compliance for patients living with a chronic disease.

In conclusion, the cook-off competition blended the relevance of basic science with empathy towards the patient experience. In addition, in the social constructivism of food preparation, learning was a fun bonding experience resulting in collaboration and friendship within the student class.

\section{Abbreviations}

PBL, problem-based learning; TBL, team-based learning; MSUD, maple syrup urine disease; MCAD deficiency, medium-chain acyl-CoA dehydrogenase; PKU, Phenylketonuria.

\section{Funding}

There is no funding to report.

\section{Disclosure}

The authors report no conflicts of interest in this work.

\section{References}

1. Kulasegaram KM, Martimianakis MA, Mylopoulos M, Whitehead CR, Woods NN. Cognition before curriculum: rethinking the integration of basic science and clinical learning. Acad Med. 2013;88 (10):1578-1585. doi:10.1097/ACM.0b013e3182a45def
2. Dahle LO, Brynhildsen J, Behrbohm Fallsberg M, Rundquist I, Hammar M. Pros and cons of vertical integration between clinical medicine and basic science within a problem-based undergraduate medical curriculum: examples and experiences from Linkoping, Sweden. Med Teach. 2002;24(3):280-285. doi:10.1080/ 01421590220134097

3. Bauler TJ, Cole S, Gibb T, Van Enk R, Lutwick L, Dickinson BL. HIV/AIDS: a case-based learning module for first-year medical students. J Microbiol Biol Educ. 2018;19(2):jmbe-19-78.

4. Helyer R, Dickens P. Progress in the utilization of high-fidelity simulation in basic science education. Adv Physiol Educ. 2016;40 (2):143-144. doi:10.1152/advan.00020.2016

5. Adams P. Exploring social constructivism: theories and practicalities. Education. 34(3):243-257. doi:10.1080/03004270600898893

6. Stangl S. Teaching nutritional concepts by integrating basic science and introductory clinical courses. Acad Med. 1997;72(5):420. doi:10.1097/00001888-199705000-00044

7. Tobin B, Welch K, Dent M, Smith C, Hooks B, Hash R. Longitudinal and horizontal integration of nutrition science into medical school curricula. $J$ Nutr. 2003;133(2):567S-72S. doi: $10.1093 / \mathrm{jn} / 133.2 .567 \mathrm{~S}$

8. Ornish D, Scherwitz LW, Billings JH, et al. Intensive lifestyle changes for reversal of coronary heart disease. JAMA. 1998;280:2001-2007. doi:10.1001/jama.280.23.2001

9. Knowler WC, Barrett-Connor E, Fowler SE, et al. Reduction in the incidence of type 2 diabetes with lifestyle intervention or metformin. N Engl J Med. 2002;346:393-403.

10. Devries S, Dalen JE, Eisenberg DM, et al. A deficiency of nutrition education in medical training. Am J Med. 2014;127(9):804-806. doi:10.1016/j.amjmed.2014.04.003

11. Vetter L, Herring SJ, Sod M, Shah NR, Kalet AL. What do resident physicians know about nutrition? An evaluation of attitudes, self-perceived proficiency and knowledge. J Am Coll Nutr. 2008;27 (2):287-298. doi:10.1080/07315724.2008.10719702

12. Mogre V, Stevens F, Aryee P, Amalba A, Scherpbier A. Why nutrition education is inadequate in the medical curriculum: a qualitative study of students' perspectives on barriers and strategies. BMC Med Educ. 2018;18(1):26. doi:10.1186/s12909-018-1130-5

13. Zoberi K, Deckert J. Simulated grocery store, restaurant, and kitchen: a practical approach to teaching clinical nutrition. MedEdPORTAL. 2007;3:745.

14. Anderson M. Biochemistry and molecular biology PBL cases. MedEdPORTAL. 2006;2:210. doi:10.15766/mep_2374-8265. 210

15. Anderson M. A matter of principle. MedEdPORTAL. 2007;3:811. doi:10.15766/mep_2374-8265.811

16. Gromley Z, Gromley A. Hemolytic anemias vs. anemias due to nutritional deficiencies: A TBL module. MedEdPORTAL. 2015;11:10304. doi:10.15766/mep_2374-8265.10304

17. Nishimoto S, Brescia W, Chesney R, et al. Type 2 diabetes TBL for M1 students. MedEdPORTAL. 2014;10:9979. doi:10.15766/ mep_2374-8265.9979

18. White CB. Smoothing out transitions: how pedagogy influences medical students' achievement of self-regulated learning goals. $A d v$ Health Sci Educ Theory Pract. 2007;12(3):279-297. doi:10.1007/ s10459-006-9000-z

19. Bonwell CC, Eison JA, George WU. Active Learning: Creating Excitement in the Classroom. Washington, DC: ERIC Digest; 1991: ED340272.

20. Dreibelbis T, George D. An intergenerational teaching kitchen: reimagining a senior center as a shared site for medical students and elders enrolled in a culinary medicine course. $J$ Intergener Relatsh. 2017;15(2):174-180. doi:10.1080/15350770.2017.129 4438

21. Halperin EC. Preserving the humanities in medical education. Med Teach. 2010;32(1):76-79. doi:10.3109/01421590903390585 
22. Hennrikus E, Skolka M, Hennrikus N. Applying metacognition through patient encounters and illness scripts to create a conceptual framework for basic science integration, storage and retrieval. $\mathrm{J} \mathrm{Med}$ Educ Curric Dev. 2018;5:2382120518777770. doi:10.1177/2382120 518777770

23. He B, Prasad S, Higashi R, Goff $H$. The art of observation: a qualitative analysis of medical students' experiences. BMC Med Educ. 2019;19:234. doi:10.1186/s12909-019-1671-2

24. Farquhar J, Kamei R, Vidyarthi A. Strategies for enhancing medical student resilience: student and faculty member perspectives. Int J Med Educ. 2018;9:1-6. doi:10.5116/ijme.5a46.1 ccc

25. Braun V, Clark V. Using thematic analysis in psychology. Qual Res Psychol. 2006;3(2):77-101. doi:10.1191/1478088706qp063oa
26. Kiger ME, Varpio L. Thematic analysis of qualitative data: AMEE Guide No. 131. Med Teach. 2020;202:1-9. doi:10.1080/ 0142159X.2020.1755030

27. Ramani S, Mann K. Introducing medical educators to qualitative study design: twelve tips from inception to completion. Med Teach. 2016;38(5):456-463. doi:10.3109/0142159X.2015.1035244

28. Hamburg M, Finkenauer C, Schuengel C. Food for love: the role of food offering in empathic emotion regulation. Front Psychol. 2014;5:32. doi:10.3389/fpsyg.2014.00032

29. Bloom BS. Taxonomy of Educational Objectives, Handbook I: The Cognitive Domain. New York: David McKay Co Inc; 1956.

\section{Publish your work in this journal}

Advances in Medical Education and Practice is an international, peerreviewed, open access journal that aims to present and publish research on Medical Education covering medical, dental, nursing and allied health care professional education. The journal covers undergraduate education, postgraduate training and continuing medical education including emerging trends and innovative models linking education, research, and health care services. The manuscript management system is completely online and includes a very quick and fair peer-review system. Visit http://www.dovepress.com/testimonials.php to read real quotes from published authors. 